\title{
A carnavalização hiperbólica da Macau Setecentista num soneto de Bocage (c.1789) em prol da figura do ouvidor Lázaro da Silveira Ferreira ${ }^{1}$
}

Rogério Miguel PUGA

O presente estudo analisa a representação sócio-histórica de Macau no soneto "Um governo sem mando, um bispo tal", de Manuel Maria Barbosa du Bocage (1765-1805), detendo-se na estada do poeta no enclave, no contexto de produção e nos objectivos políticos do processo de carnavalização que caracteriza a composição poética, ocupando-se também forçosamente da relação entre o mundo possível textualizado por Bocage de forma realista e os referentes extra-textuais para os quais o soneto remete. Como já afirmámos anteriormente (PugA, 2009a, p. 31-32), o conceito de literatura - enquanto fenómeno social e construção

\footnotetext{
1 Artigo já publicado no n. 49 da Revista de Cultura (Instituto Cultural de Macau, Macau), em 2015, p. 6-22.

2 Doutorado em Estudos Anglo-Portugueses (2007), foi Professor Auxiliar na Universidade de Macau (2007-2009) e é Investigador Auxiliar na FCSH/Nova e Professor Adjunto Convidado no Instituto Politécnico de Lisboa; rogerio_puga@hotmail.com
} 
ou poiesis histórico-antropológica,$-{ }^{3}$ bem como as complexas relações entre a história e a literatura, e nomeadamente a poesia, ${ }^{4}$ são cada vez mais estudados de forma interdisciplinar. ${ }^{5}$ Como veremos, o poema de que nos ocupamos carnavaliza e caracteriza de forma hiperbólica o contexto histórico da Macau do final do século XVIII (o tempo da escrita), sendo actualmente um repositório textual desse período histórico da urbe para leitores que têm assim acesso a essa representação subjectiva e simultaneamente politica e literária. Maria de Fátima Marinho estuda as relações entre o passado e a sua transposição para a escrita, afirmando que estas são "sempre difíceis mas também sempre sedutoras", sobretudo devido ao facto de a história ter tomado consciência da impossibilidade de produzir um discurso único e definitivo sobre acontecimentos reais e de o romance não ser um género estável nem coerente. ${ }^{6}$ Maria Alzira Seixo, ao abordar a questão, resume essas relações a partir de quatro perspectivas de trabalho, a saber: 1) através da história literária (captação do sentido evolutivo dos modos de escrever, ler, ensinar e difundir a literatura); 2) através da interdisciplinaridade que convoca o conhecimento da história e da literatura, entendendo os estudos literários como intersecção do espaço das ciências da linguagem e dos estudos de estética com o das ciências históricas, ou seja, o estudo do relacionamento entre a poética (cenas de efabulação) e a historicidade (cenas de convocação histórica); 3) através

3 Vide Manuel Gusmão (2001, p. 181-224).

4 Roundell Palmer (1852), Emery Neff (1961) e Paul A. Bové (2008).

5 Sobre a relação entre literatura e história, vejam-se Lionel Gossman (1990, p. 227-256); Dirce Côrtes Riedel (1998); Luiz Eugénio Véscio e Pedro Brum (1999); David Der-wei Wang (2004, p. 1-40, 183-223); Maria de Fátima Marinho e Francisco Topa (2004), e Maria de Fátima Marinho (2005).

6 Maria de Fátima Marinho (2005, p. 9-20). 
do estudo da história em geral entendida como memória de um passado humano colectivo passível de ser reconstituída e alterada verbalmente e, portanto, tema ou motivo de textualização literária, e 4) através da acepção da história como movimento accional de um texto, como intrincado de problemas e actuações, e como intriga ou efabulação, pois contar uma história é remeter para situações idênticas que se reportam a um mundo "real" (circunstancial) e ao imaginário da memória comum. ${ }^{7}$ Para o estudo do soneto "Um governo sem mando, um bispo tal", de Bocage, interessam-nos sobretudo estas três últimas relações entre literatura e história, ou seja a história quer como efabulação quer como estratégia, tema ou motivo literário. Analisaremos assim de que forma a literatura e a história se podem questionar mutuamente no poema, de que modo a história se assume ou pode ser implicada ou convocada como elemento estruturante do poema e quais os limites da representação da ideologia e da história na literatura em geral. Só conhecendo a história da Macau Setecentista que o poema tenta caracterizar com base em fortes juízos de valor poderemos estudar esse texto em profundidade e descodificá-lo à luz da realidade extra-textual para que este remete.

A biografia de Manuel Maria Barbosa du Bocage é já bastante conhecida, bastando-nos reter apenas alguns factos para a compreensão da sua viagem-fuga até Macau, que lhe permite carnavalizar a urbe no referido soneto. A vertente carnavalesca da sua obra está presente inclusive num auto-retrato em que prevalece a auto-caricaturização algo dionisíaca:

7 Síntese elaborada a partir de Maria Alzira Seixo (2004, p. 231-241). 
Magro, de olhos azuis, carão moreno,

Bem servido de pés, meão na altura,

Triste de facha, o mesmo de figura,

Nariz alto no meio, e não pequeno;

Incapaz de assistir num só terreno,

Mais propenso ao furor do que à ternura;

Bebendo em níveas mãos, por taça escura,

De zelos infernais letal veneno;

Devoto incensador de mil deidades

(Digo, de moças mil) num só momento,

E somente no altar amando os frades,

Eis Bocage, em quem luz algum talento;

Saíram dele mesmo estas verdades,

Num dia em que se achou mais pachorrento. (1969, p. 3)

O carnavalesco (ou carnavalizado) mundo bocageano foi também descrito pelo excêntrico viajante britânico William Beckford após um encontro com o poeta luso entre 1793 e 1795. Em Italy, with Sketches of Spain and Portugal, o escritor descreve Bocage através de sugestivos adjectivos:

[...] the queerest, but perhaps, the most original of God's poetical creatures. He happened to be in one of those eccentric, lively moods, which, like sunshine in the depth of the winter, come on when least expected. A thousand quaint conceits, a thousand flashes of wild merriment, a thousand satirical darts shot from him, and we were all convulsed with laughter...Indeed, this strange and versatile character may be said to possess the true wand of enchantment, which, at the will of its master, either animates or petrifies. (1834, p. 204-205) 
Essa mesma imagem continua a ecoar na literatura portuguesa, como podemos verificar através de, por exemplo, o título do romance de Luís Rosa, Bocage, a Vida Apaixonada de um Genial Libertino (2006), e do anedotário popular que é, embora injustamente, associado a Bocage em Portugal e no Brasil.

\section{A viagem rumo ao Oriente}

Em 1786 o oficial da Marinha Bocage viaja para Goa no Nossa Senhora da Vida, Santo António e Madalena, visitando o Rio de Janeiro (junho) e Moçambique (setembro). O poeta chega a Goa no final de Outubro desse ano e torna-se amigo do juiz-poeta Sebastião José Ferreira Barroco (1777-1802), ajudando a controlar a chamada Conspiração dos Pintos (1787). ${ }^{8}$ Bocage descreve a capital do império português asiático e, mais tarde, Macau, como cidades decadentes. Goa encontrava-se então em ruínas, imagem que em 1851 também Sir Richard Francis Burton (1821-1890)9 enfatizaria, sendo esse mesmo simbólico e alegó-

8 Teófilo Braga (1902, p. 55-57).

9 Conforme Richard Francis Burton descreve em Goa and the Blue Mountains or Six Months of Sick Leave (1851) de Pangim, o viajante vitoriano parte para Velha Goa e descreve-a "as it was" no capítulo terceiro - através de intertextos históricos que convoca para o tecido arqueológico do seu próprio texto -, e "as it is" no capítulo quarto, textualizando o passado de monumentos imperiais então em ruínas. A velha e isolada Goa é apresentada como uma cidade cronotópica, um espaço histórico palimpséstico onde ser descobrem diversas camadas escondidas ou esbatidas pelo passado e reveladas por antigos relatos de viagem. Os diferentes edifícios simbolizam os diversos tipos de poder, o palácio remete para o poder religioso e político, a alfândega para o económico e comercial e para os cofres centrais da metrópole, enquanto as estátuas de Afonso de Albuquerque e o arco dos vice-reis (60) remetem para os poderes administrativo e militar, estando muitos desses monumentos, alegorias do poder colonial português, ao abandono (61). O choque do encontro-confronto de Burton com a realidade Outra e com o espectáculo duplo da alteridade é metaforizado através da arquitectura, como revela a expressão: "monotony of 
rico espaço colonial português apresentado de forma negativa pela voz crítica do sujeito poético, como um "ermo":

Das terras a pior tu és, ó Goa,

Tu pareces mais ermo, que cidade;

Mas alojas em ti maior vaidade que Londres, que Paris, ou que Lisboa. ${ }^{10}$

Em fevereiro de 1789, o poeta boémio é promovido a tenente da Infantaria e em março é transferido para Damão, onde chega a 6 de abril. Dois dias depois, acompanhado pelo alferes Manuel José Dióniso, Bocage deserta. Os dois fugitivos deslocam-se para Surrate e daí viajam, talvez a bordo de uma embarcação britânica, para Macau. Desconhecem-se os motivos da viagem para o Sul da China, no entanto o poeta cantou aventuras na província de Cantão - espaço alargado que poderá, no entanto, remeter metonimicamente para Macau - e perigosas deambulações que, no entanto, poderão ser estratégias literárias do processo de auto-glorificação, na senda de viagens picarescas (lendárias ou reais), como as de Camões ou Fernão Mendes Pinto e

ruins" (63). Essas ruínas católicas decerto recordariam o leitor britânico das ruínas católicas no seu próprio país, fruto da Reforma Protestante de Henrique VIII trezentos anos antes. As ruínas de Goa, remetendo para as ruínas de abadias e igrejas católicas extintas no século XVI por toda a Inglaterra, sugeririam o aparecimento de uma nova ordem, e talvez seja essa a mensagem subliminar do texto quando Burton afirma: que parece que "a curse has fallen upon Old Goa where the Inquisitio ruled" (62). Sobre as ruínas católicas de Velha Goa nascerá uma nova ordem protestante, vinda da Índia britânica. A Goa empobrecida e ofuscada pelas cidades portuárias britânicas na Índia, como Bombaim, já não é visitada por mercadores importantes, continua a tolerar a convivência de diferentes religiões e foi esquecida por Roma. O exercício da intertextualidade, como vimos, serve assim o propósito de enfatizar a velha glória de Goa, agora desaparecida, tal como a pujança do império luso, ao contrário do poderoso império britânico.

10 Vide Ethel M. Pope (1937, p. 180), Gomes Monteiro (1943, p. 63), e o romance de Luís Rosa, Bocage, a Vida Apaixonada de um Genial Libertino (2006, p. 102). 
que exigem o confronto com os elementos naturais, como também Os Lusíadas demonstram através de episódios e temas como os do Fogo de Santelmo e da tempestade. Bocage 'narra' da seguinte forma as suas viagens:

\section{Por bárbaros sertões gemi vagante}

Até que os mares da longínqua China.

Fui por bravos tufões arrebatado. ${ }^{11}$

O poeta auto-caracteriza-se assim como um escritor picaresco no Oriente de cariz lusófono, na senda de Mendes Pinto, que antecede Wenceslau de Morais e Camilo Pessanha. Na elegia de Bocage à morte do príncipe D. José (m. 11-09-1788), lemos ainda:

Triste povo! E mais mísero eu, que habito

No remoto Cantão, donde, Ulisseia,

Não pode a ti voar meu débil grito!

Misérrimo de mim que em terra alheia. ${ }^{12}$

O poeta desertor deverá ter residido em Macau entre setembro-outubro de 1789 e março de 1790, uma cidade governada pelos mercadores do Senado, ${ }^{13}$ pelo Ouvidor e pelo Governador, bem como pelo poder religioso, todos eles directa ou indirectamente visados no poema de que nos ocuparemos. Em Macau, Bocage tornou-se amigo do capitão-geral/governador Lázaro da Silva Ferreira, que juntamente com outro governador interino,

11 Teófilo Braga, (1902, p. 73).

12 Vejam-se Teófilo Braga (1902, p. 74) e Mário Domingues (1962, p. 149).

13 Arquivo Histórico Ultramarino (AHU), caixa 6, doc. 35. 
o major Manuel da Costa Ferreira, comandante do Presídio, substituíra Francisco Xavier de Mendonça Corte Real, em 16 de Julho de 1789 (após a morte deste último), governando até 29 de Julho do ano seguinte, altura em que Vasco Luís Carneiro de Sousa Faro se torna governador. O ouvidor-governador Lázaro da Silva Ferreira não acusa o poeta de desertar de Damão e inclusive tê-lo-á auxiliado a regressar a Lisboa, onde Bocage chega em Agosto de 1790, agradecendo ao governador através de um poema, uma prática que aliás se estende a outros seus benfeitores do enclave. O escritor teria sido apoiado em Macau e no regresso a Portugal também por Maria Joaquina de Saldanha Noronha e Meneses, ${ }^{14}$ a quem dedica a ode "O Adeus", ${ }^{15}$ redigida no final de 1789 e que elogia a beleza quer da "piedosa e magnânima" (TeixeIrA, 1997, p. 279) senhora "Marília" que "enche $[. .$.$] de glória a fertile China", quer das "lindas filhas"$ dela (TeixeIRA, 1997, p. 279), pedindo-lhe que o ajude a voltar para Portugal. O poeta escreve ainda outra ode dedicada a Maria de Guadalupe Topete Ulhoa Garfim, residente de Macau que é descrita como "semi-deusa gentil" (TeixeirA, 1997, p. 281). Como prova a 'Rua do Bocage' no território, o poeta viajante faz ainda hoje parte da memória colectiva de Macau.

Elmano Sadino instalou-se temporariamente em Macau e regressou à Europa também com o apoio do comerciante Joaquim Pereira de Almeida, que chegara ao território por volta de 1787, chamando-lhe o poeta "meu benfeitor, meu caro ami-

14 Casou em 1774 com Bernardo Aleixo de Lemos Faria, governador de Macau (17831788) e teve duas filhas, Ana Isabel de Lemos Saldanha e Mariana Xavier de Lemos Saldanha.

15 Bocage (2005); ode originalmente publicada em Noites de Évora (1897) e posteriormente no Jornal de Letras, Artes e Ideias (04-17 janeiro 2006, p. 19). Veja-se Adelto Gonçalves (2003, p. 147,458$)$. 
go" (GonçALVEs, 2003, p. 147) numa elegia que lhe oferece por ocasião da morte de seu pai, escrita em Lisboa, quando ambos já estavam em Portugal. Joaquim Almeida foi sobrecarga da nau Marquês de Angeja e talvez Bocage tivesse deixado Macau com destino a Lisboa nessa embarcação no início de Janeiro de 1790. No soneto "Aos Amigos", publicado em Improvisos de Bocage na sua mui Perigosa Enfermidade, o poeta caracteriza Almeida como "humano" (GonçALVES, 2003, p. 147), sendo o homenageado também amigo do já referido governador interino, ouvidor e juiz-administrador da alfândega Lázaro da Silva Ferreira.

O juiz-governador Silva Ferreira tomou posse na Ouvidoria de Macau quando esta foi restabelecida em 1785 e, como já referimos, beneficiou o poeta quando ele chegou ao território como desertor, ignorando esse crime (GonçAlves, 2003, p. 142-147). O poeta dedicou ao juiz a ode sáfica "A Gratidão", na qual confessa: "Tudo a ti devo, ó benfeitor, ó grande.../Tudo te devo: a gratidão não sofre/Que teus favores generosos cale...//Ó céus! Ó fados! Conservai Ferreira;/São necessários os heróis no mundo:/E tu ferrolha os porcelosos monstros,/Éolo amigo" (TeixeIra, 1997, p. 282-283). Após tomar posse, o juiz repôs a ordem nas finanças quer da administração pública da cidade, quer da Santa Casa da Misericórdia, gerando assim inimigos locais que desviavam verbas para causas pessoais e de grupos de interesse. No Verão de 1787, já o Senado e o governador Sousa Faro haviam tentado, em vão, junto de Goa, acusar o juiz de conflitos entre portugueses e chineses e destituí-lo, ${ }^{16}$ mas Ferreira apenas foi substituído como juiz, por António Pereira dos Santos, a 15

16 AHU, caixa 17, docs. 3 e 68; caixa 18, docs. 21 e 34; caixa 19, docs. 7 e 34; caixa 20, docs. 10-11; caixa 21, doc. 5; os parágrafos 30-37 das "Instruções", p. 13-16 e António Martins do Vale (1997, p. 16-17). 
de Maio de $1797 .{ }^{17} \mathrm{O}$ magistrado fora nomeado por um período de três anos, entre 1787 e 1789, e já conhecia as especificidades de Macau, pois quando da Instrução de 1783 fora incumbido de examinar os cofres públicos, estabelecer a alfândega e ajudar a instalar o Seminário de São José. Em 1787, o juiz não foi bem recebido pela população devido aos interesses instalados na urbe, pois ao acumular vários outros cargos (juiz dos órfãos, juiz de alfândega, provedor dos defuntos e dos ausentes e contador da comarca) retirava poder e espaço de manobra aos senadores que compunham o Leal Senado. O ouvidor e o governador são ainda estrategicamente culpados pelo Senado de causarem conflitos entre os portugueses e os chineses (1787), ${ }^{18}$ acusando o governador Sousa e Faro o ouvidor Silva Ferreira de corrupção e favorecimento de estrangeiros (1792, 1795, 1789). ${ }^{19}$ Já em 1783, o próprio Martinho de Melo e Castro descreve o Senado como um órgão composto "na sua maior parte de Degredados, que ali se refugiaram, ou de outros similhantes a eles, todos ignorantíssimos em matérias de Governo, e sem outras vistas mais, que as de procurarem a sua fortuna" (Melo E Castro, 1988, p. 11). Como veremos, o poema de que nos ocupamos ecoa quer essa imagem negativa sobre os (oportunistas) moradores de Macau - que era então repetida por parte do discurso político de Goa e de Lisboa (Martinho de Melo e Castro), e até de Macau [ouvidor Lázaro da Silva Ferreira, governadores Bernardo Aleixo de Faria (17831788) e Vasco Luís Sousa e Faro (1790-1793)], sobretudo a partir de 1770 - , quer os referidos jogos de interesses locais e a submissão dos moradores perante as autoridades chinesas devido a

17 AHU, caixa 18, docs. 21, 44.

18 AHU, caixa 18, docs. 21, 34, caixa 19, doc. 7, caixa 21, doc. 5 .

19 AHU, caixa 19, doc. 34, caixa 20, docs. 10-11, caixa 21, doc. 5 . 
interesses locais (lucros). ${ }^{20}$ Torna-se assim importante atentar no uso da história como temática literária e ferramenta ideológica no texto bocageano que transcrevemos de seguida.

\section{O Soneto}

Um governo sem mando, um bispo tal, A

De freiras virtuosas um covil B

Três conventos de frades, cinco mil B

Nhon's e chinas cristãos, que obram mui mal; A

Uma Sé que hoje existe tal e qual A

Com catorze prebendados sem ceitil; B

Muita pobreza, muita mulher vil, B

Cem portugueses, tudo em um curral; $\quad$ A

Seis Fortes, cem soldados e um tambor, C

Três Freguesias, cujo ornato é pau, D

Um Vigário Geral, sem promotor; C

Dois colégios, e um deles muito mau, D

Um Senado que a tudo é superior; C

É quanto Portugal tem em Macau. ${ }^{21}$ D

20 Veja-se António Martins do Vale (1997, p. xvi-xix).

21 Bocage, Obra Completa, vol. 1: Sonetos, edição de Daniel Pires, Porto: Edições Caixotim, 2004, soneto n. 196. A mais recente edição da Obra Completa é da responsabilidade de Daniel Pires, presidente do Centro de Estudos Bocageanos, de Setúbal e é publicada pela Edições Caixotim (Porto): vol. 1: Sonetos (2004), vol. 2: Cantatas, canções, idílios, epístolas, odes e cantos (2005), vol. 3: Apólogos ou fábulas morais, epigramas, poesia sobre mote, poesia anacreôntica, endechas, elegias, epicédios (2007), vol. 4: Sátiras, madrigal, poesias várias, epitáfios, improvisos, elogios dramáticos, elogios à família Real, dramas, prólogos de peças teatrais, fragmentos dramáticos, fragmentos, anexos (2007), vol. 7: 
Como revela a leitura do soneto 'político', o sujeito poético serve-se da enumeração, da adjectivação e de substantivos com carga negativa ("covil", "mal", pobreza", "vil", "curral", "mau"), bem como da aliteração (sibilante) para criticar, de forma hiperbólica, o ambiente social, religioso e político da urbe, detendo-se apenas nos aspectos negativos. O queixume acentua a imagem algo triste de um território decadente e abandonado por Lisboa. Trata-se de um crítica e de um possível pedido de ajuda para Macau, uma quase certidão de óbito através do exercício da carnavalização, sobrepondo-se claramente o projecto ideológico/político ao valor estético do poema, que é claramente reduzido. O verbo 'ter' remete simultânea e simbolicamente para a posse (sinónimo de manter) e, de forma irónica e crítica, para o abandono (sinónimo de má manutenção política por parte da metrópole imperial e do governo local, o Senado). São assim apresentados cumulativamente: o paradoxal covil de freiras virtuosas, o débil governo sem rumo político, bem como o fraco poder religioso que se faz simbolizar por uma sé catedral decadente, quando deveria exibir alegorias do seu poder com opulência e grandiosidade num território em que maioria das mulheres é vil. Se Bocage critica o Senado também afirma que o território se encontra no estado miserável de que ele é testemunha devido ao abandono por Lisboa, pelo que urge ajudar a manter Macau de uma forma digna, como aliás o discurso político advogava em Portugal, nem que para tal se tivesse que retirar autonomia à edilidade do território, medida a que os moradores resistem, por exemplo, logo entre 1741-1742, 1749-1752, passando a ser alvo da desconfiança de alguns políticos na metrópole. No en-

Poesias eróticas burlescas e satíricas. (2004), e contempla muitos poemas ausentes das (anteriores) edições de Inocêncio Francisco da Silva, Teófilo Braga e Hernâni Cidade. 
tanto, há diversas fontes em que religiosos e administradores elogiam os moradores de Macau. O bispo de Macau entre 1772 e 1789, D. Alexandre da Silva Pedrosa Guimarães, enaltece os moradores (1775), ${ }^{22}$ e o seu sucessor D. Marcelino José da Silva conclui, em 1791, já na cidade, que os seus moradores eram "mais dóceis" e "susceptiveis de rezão" do que se afirmava em Lisboa. ${ }^{23}$ Em 1776 o capitão-tenente Nicolau Fonseca descreve esses moradores como fieis ao reino. ${ }^{24}$ Ao contrario desses residentes, Bocage prefere enfatizar estrategicamente a imagem negativa dos habitantes de Macau, hiperbolizando-a. Sobre os juízos extremados acerca da acção dos moradores, António Vale (1997, p. xix) conclui que a conjuntura política portuguesa de então e o espaço reduzido de manobra desses mesmos agentes coloniais na China facilitou a primazia do discurso negativo. Independentemente das críticas e das medidas repressivas, os interesses locais muitas vezes falaram mais alto do que as leis de Lisboa ou Goa, sendo estas frequentemente ignoradas quando chocavam com os lucros da edilidade local. ${ }^{25}$

A caracterização de Macau como um curral pobre e decadente é elaborada através dos exercícios da enumeração e da carnavalização de elementos da sociedade macaense, onde também não parece haver educação, espiritualidade-religiosidade, nem justiça, mas apenas o poder altaneiro e déspota do Senado, órgão administrativo criado em 1583 e que sempre fora a voz dos interesses da edilidade local, ou seja, dos comerciantes macaenses. Desde cedo na história de Macau, o Senado é acusado de não cumprir as ordens régias em prol de interesses e de

22 AHU, caixa 9, doc. 8.

23 AHU, caixa 19, doc. 13.

24 AHU, caixa 10, doc. 2.

25 Arquivos de Macau, (1971, p. 222-223). 
negócios familiares e locais, pois, como é sabido, os comerciantes locais dominavam o Senado, dependendo o capitão-geral ou governador - o representante do poder régio e chefe militar - economicamente do Senado. O sujeito poético atenta assim apenas nas dimensões negativas de Macau, hiperbolizando-as sobretudo aos níveis arquitectónico e social. A administração do Senado - órgão que tem poder absoluto e parece não respeitar ninguém, nem mesmo os representantes régios (governador e ouvidor) - é criticada; daí que o texto adquira circularidade temática, pois abre com a questão do falta de governo e no final revela que esse desgoverno se deve ao poder (mau e) desmesurado do Senado, instituição que não se deixa disciplinar, nem mesmo pelo juiz provedor.

A textualização poética do mundo às avessas da cidade histórica e semi-colonial de Macau exige assim uma análise do soneto à luz do conceito bakhtineano de 'carnaval'. ${ }^{26}$ Como é sabido, podemos atribuir dois sentidos ao termo 'Carnaval': a) as festividades ritualizadas no mês de Fevereiro que reavivam a cultura popular quer da feira medieval, quer das festas que antecedem a Quaresma, e b) o carnaval enquanto aplicação dessa mesma consciência na literatura (paródia) de forma a usar esse espírito carnavalesco para denunciar e criticar excessos ao

26 Para análises da teoria do Carnaval de Bakhtin, vejam-se: Terry Castle (1987; 1984, p. 912) ("lirical theory"); Michael Gardiner (1992, p. 180) ("fulsome and naive"). Sobre críticas à visão essencialista da transgressão carnavalesca por parte de Bakhtin, vejam-se: Emmanuel LeRoy Ladurie (1979, p. 229); Terry Eagleton (1981, p. 148); Michael Bristol (1985); Linda Hutcheon (1985, p. 71-75); Robert Young (1985-1986, p. 71-92); Michael Andre Bernstein (1996, p. 9-121); Richard M. Berrong (1986); Leonard Tennenhouse (1986, p. 79); Peter Stallybrass e Allon White (1986); Gary Saul Morson e Caryl Emerson (1989, p. 433-472); Marvin K. Booker (1991); Paul Strohm (1992, p. 33-56); Konrad Eisenbichler, "Introduction" (1999); Caryl Emerson (2000); Rocco Coronato (2003); Meghan Christine Vicks (2007, p. 1-8), Benjamin Rollins (2012). 
modo, por exemplo, de Gil Vicente, processo a que chamamos carnavalização da literatura: "the transposition of carnival into the language of literature" (1984a, p. 122). O carnavalesco interessa-nos como forma de pensamento e como universo representado na literatura, ${ }^{27}$ sendo simultaneamente um modo de representação, um termo-conceito operacional, um fenómeno textual e um tropo para desconstruir e subverter parodisticamente que sobrevive principalmente como conceito no âmbito da Teoria Literária, e não tanto da História Social. ${ }^{28}$ De acordo com Lindley:

$[\ldots]$ it does so because it describes an element, a process of demystification, manifestly present in a great range of Western literature, whatever the social sources or political consequences, if any, of that element may have been outside the texts. Bakhtin is not writing [...] about social behaviour but about the ways in which social practice ("carnival") is refracted and remained in literary texts (“carnivalesque”). (1996, p. 22)

O carnaval(esco) de Bakhtin interessa-nos quer enquanto um modo literário de (compreender e) representar o mundo, quer enquanto ferramenta analítica ${ }^{29}$ para estudar o mundo às

27 David K. Danow (1995, p. 4-22), vejam-se também: Aron Gurevitch (1988, p. 176210); Ken Hirschkop, (1989, p. 3, 34); Arthur Lindley (1996, p. 17-27); Charles Platter (2001, p. 55).

28 Arthur Lindley (1996, p. 22, 70); Katherina Clark e Michael Holquist (1984, p. 304312); Peter Stallybrass e Allon White (1986, p. 6-8); Nancy Glazener (1989, p. 113); R. Stam (1989, p. 96); Sue Vice, Introducing Bakhtin (1997, p. 149-156); Dan Krier e William J. Swart (2012, p. 135-168).

29 Stallybrass e White (1986, p. 7-8) definem o carnavalesco como uma categoria epistemológica e uma potente inversão crítica de todas as hierarquias oficiais, um mundo onde tudo se encontra degradado e sem identidade. Emerson (2000, p. 203-204) sumari- 
avessas no soneto de Bocage. Como o poema revela, o carnavalesco é também uma visão parodística, subversiva e até indecorosa, uma estratégia literária através da qual a vida religiosa, política e social de Macau é reduzida ao universo de um indecoroso e vazio curral, sem lei nem qualquer traço de espiritualidade, civilidade ou cultura. Trata-se de uma visão (HirschKop, 1989, p. 35) que, no soneto, faz parte de um projecto político próximo do espírito do Carnaval que celebra "temporary liberation from the prevailing truth and from the established order" e marca "the suspension of all hierarchical rank, privileges, norms and prohibitions" (BAKHTIN, 1984b, p. 10), pelo que não há um poder legítimo vigente em Macau, nem disciplina, a não ser a dos interesses privados, tornando-se a urbe "a space of and for fantasy" (Chedgzoy, 2000, p. 56, 62). O Carnaval é a festa também da renovação, sendo usado por Bocage como ferramenta literária e ideológica (política) para satirizar e criticar os poderes e até a população de uma Macau deserta e animalizada, que se deve renovar. Se o Carnaval pode ser interpretado como uma metáfora crítica (STEWART, 1984, p. 143-145), a desordem institucional, o imaginário corporal grotesco, a cultura não oficial e a inversão ritual são elementos do "carnival sense of the world" estudado por Bakhtin (1984a, p. 107-108, 123, 158) e outros autores e que existe no poema bocageano, sobretudo ao nível temático.

Como é sabido, em Macau o governador dependia financeiramente do Senado pelo que nunca poderia gozar de autonomia plena, dedicando-se apenas à esfera militar. ${ }^{30}$ Não seria,

\footnotetext{
za as três principais linhas do 'carnival rethinking' no pensamento contemporâneo: como um ritual sacralizado, como uma alegoria demonizada ou estalinizada, com as formas mais neutrais de o encarar como um artifício analítico nos estudo literários: "we cultivate laughter as a route to knowledge. This was Bakhtin's point".
}

30 Veja-se António Martins do Vale (1997, p. 2-15.) 
portanto, de estranhar que quer o Conselho Ultramarino, em 1735 e 1750, quer o secretário de estado da Marinha e Ultramar, Martinho de Melo e Castro, em 1783, achassem que era "necessário dar maior autoridade aos Governadores de Macau, e muni-los de alguma força militar, que os faça mais respeitados". ${ }^{31}$ O político pretende que o governador passe a presidir no Senado e a intervir na administração da fazenda real para assim se fortalecer o mitigado poder do representante régio. No entanto, a corrupção era também comum entre os governadores, ${ }^{32}$ que se associavam ao Senado para obter lucros pessoais, como o próprio Silva Ferreira recorda a Martinho de Melo e Castro em 1784 relativamente a Salema de Saldanha. ${ }^{33}$ Se o governador era, em nome da Coroa, a primeira autoridade em Macau, não tinha qualquer poder real e eficaz, sendo a sua relação com o Senado marcada pela permanente tensão que advém da medição de forças. ${ }^{34}$

$\mathrm{O}$ último terceto do poema encerra a chave interpretativa do poema, ao revelar a crítica ao (des)governo do Senado, atribuindo-lhe as culpas pelo estado degradado da sociedade local. A leitura bakhtineana do soneto permite-nos concluir que o sujeito poético pede a Lisboa que ponha termo ao caos do Carnaval imposto pelo Senado e traga a ordem simbólica da Quaresma a Macau, pelo que seria o governo apolíneo e equilibrado do governador que travaria o séquito e a desordem dionisíaca na vida pública e na sociedade de Macau. Aliás, a documentação redigida pelo ouvidor (PIRES, 1988, p. 72) corrobora a imagem

31 Parágrafo 19 das "Instruções a D. Frederico Guilherme de Sousa" (Múrias, 1988, p. 7) e AHU, caixa 6, doc. 47.

32 AHU, caixas 17, doc. 26, e 19, doc. 30, parágrafo 18 da "Instrução", p. 18.

33 AHU, caixa 16, doc. 3

34 Cf. António Martins do Vale (1997, p. 15, 35-59). 
do território administrativa e socialmente degradado veiculada pelo poema escrito pelo seu amigo protegido Bocage, ou seja, o soneto ecoa apenas a opinião do juiz relativamente aos aspectos que ele critica em Macau. Os já referidos confrontos entre a população e o juiz Ferreira surgem do controle por ele exercido na administração do território, até então da responsabilidade do Senado e da edilidade local, levando a chegada do juiz a novas restrições na administração pública. O próprio Lázaro Ferreira reconhece em 1790 que todas as "reais providências têm sido sumamente odiosas aos moradores de Macau, quase todos clamam pela novidade delas, refugiando-se na calúnia, e na falsidade com que procuram iludi-las [...], não querem Ouvidor que lhes lembre as dívidas, que lhes dificulte empréstimos novos, ou os obrigue a pagarem os antigos". ${ }^{35}$ Não admira, portanto, que Bocage comece por cantar a falta de governo na cidade, servindo o propósito de elogiar indirectamente a acção de controle da administração por parte do juiz seu amigo, que pretende acabar com o desgoverno referido no poema. Com efeito, a população local rejeita o ouvidor sobretudo porque reage mal às reformas de 1873 (implementadas a partir de 1874), que passariam a controlar as contas e a administração da cidade, em detrimento dos interesses (financeiros) da elite local, que perdia assim parte do seu poder e da autonomia com que até então administrava a cidade. Após um período de pouca comunicação entre Portugal e Macau (1754-1770) devido ao esforço de reconstrução de Lisboa após o Terramoto, à expulsão dos Jesuítas, ao processo dos Távora e a prioridade colonial conferida ao Brasil, em finais da década de 1760 e no início da década seguinte, o Reino, tal como

35 Carta de Lázaro da Silva Ferreira a Martinho de Melo e Castro (20-01-1789): AHU, caixa 18, doc. 21 e António Martins do Vale (1997, p. 17-19). 
Bocage faria, reconhece o abandono de Macau e decide analisar a situação do enclave (organização político-administrativa, administração da fazenda real, sociedade e economia, história de Macau) para melhor o controlar e reformar. Martinho de Melo e Castro, Secretário de Estado da Marinha e Ultramar, pede a Goa e a Macau que lhe enviem informações detalhadas sobre o território luso-chinês para preparar essa reforma administrativa. Surgem assim as "Instruções de 1783" (a D. Frederico Guilherme de Sousa) que visam estreitar a relação entre Macau e Lisboa e reduzir a autonomia local. O Senado recusa as novas reformas com a justificação de que não servem à cidade (VALE, 1997, p. 19, 59-69). Como já afirmámos, a cidade calunia e critica o desembargador quando ele regressa a Macau em 1787 para assumir o novo cargo, e mais de dez anos depois da sua chegada ainda o caracterizam como um "espírito de vaidade" e referem as ameaças de prisão com que ele exercera o seu poder. ${ }^{36} \mathrm{O}$ soneto de Bocage reflecte directa e indirectamente o contexto histórico que acabámos de apresentar, ficando claro para o leitor informado que o poeta elogia indirectamente toda a acção e o controlo do seu amigo ouvidor e critica de forma hiperbólica o estado de degradação da cidade devido aos interesses dos senadores. É portanto óbvio que o conhecimento do contexto histórico em que Bocage residiu na urbe e redigiu o poema, bem como das instituições e práticas referidas no soneto nos permitem uma interpretação mais profunda da que surgiria se tivéssemos atentado apenas (ou sobretudo) na vertente estética/literária desse texto.

O incipit aliterativo do soneto remete para a administração portuguesa do enclave, tema que indica logo o cariz sobretudo políti-

36 Representação do Senado à rainha (20-03-1798), AHU, caixa 21, doc. 5 e António Martins do Vale (1997, p. 19). 
co do texto. Essa atitude por parte de Bocage não é de admirar se atentarmos no apoio dado pelo governador e pela elite local ao poeta após a sua chegada e quando do seu regresso a Portugal. No entanto, também o poder religioso não tem "mando". O segundo verso caracteriza as freiras através de um único termo negativo ("covil"), sendo também enumerados os três conventos de ordens masculinas, cinco mil nhons e chineses cristãos que prevaricam. O termo do crioulo macaense 'nhon' (ou nhum; feminino: nonha) utilizado no último verso da primeira quadra significa 'senhor' e designa os homens mestiços ou crioulos do enclave. ${ }^{37} \mathrm{O}$ importante grupo étnico ou comunidade macaense marca assim presença no poema, tal como noutros textos de residentes/viajantes portugueses, nomeadamente a narrativa de viagem de Adolfo Loureiro (1896, p. 23). É ainda curioso o uso da expressão "china cristão" - que então designava ambiguamente quer os naturais de Macau (macaenses), quer os recentemente convertidos (chamados cristãos novos) — que são assim associados pelo sujeito poético ocidental aos crioulos macaenses, enquanto os reinóis são referidos num outro verso do poema. Há, portanto, uma divisão étnica, social e religiosa da população, não sendo mencionados nem os escravos, nem os estrangeiros que aí já residiam (PugA, 2009b). Aliás, a fonte "Notícias e Reflexões sobre a Cidade de Macau", redigida nessa mesma altura, descreve a comunidade portuguesa (diríamos hoje, lusófona) como constituída por "habitantes da dita cidade que se compõem de Portugueses nascidos em Portugal [reinóis], de Portugueses nascidos na Índia, a que se chamam mestiços, de Chinas Cristãos que não têm sangue Português, a que chamam naturais, de escravos cafres e

37 Veja-se Graciete Nogueira Batalha (1977, p. 229-230). A autora afirma que a forma tem origem provável nos dialectos afro-portugueses (por exemplo, de Cabo Verde). 
Timores". ${ }^{38}$ Os chineses cristãos eram considerados e incluídos pelos portugueses no grupo dos vassalos do rei de Portugal, embora ficassem sob a alçada do Mandarinato, que administrava os 30000 chineses que em 1788 residiam em Macau. ${ }^{39}$ As freiras a que o sujeito poético se refere eram as clarissas (do Convento de Santa Clara), afirmando o padre Manuel Teixeira que "a palavra 'covil' referia-se à clausura rigorosa dessas freiras" (TeIXeIRA, 1997, p. 284). As clarissas eram consideradas "honradas" como revela o relatório do bispo de Macau D. Alexandre Guimarães (1775), que, por sua vez, critica os franciscanos e agostinhos por não viverem como religiosos mas em permanente festa, ${ }^{40}$ ou seja, preferindo o 'Carnaval' à 'Quaresma'. As clarissas encontravam-se em Macau, vindas de Manila, desde 1633 e eram sobretudo uma comunidade espiritual, que vivia em reclusão. O Convento de Santa Clara era a única instituição religiosa feminina, e, em Julho de 1831, a jovem unitária norte-americana Harriet Low, ao visitar a capela de Santa Clara, assiste aos votos de ingresso de uma noviça no Convento, cerimónia que tenta descodificar ao descrever o ritual de forma negativa (LOW, 2002, p. 242243). Já os três conventos referidos pelo sujeito poético são o de São Francisco - fundado no final de 1579 por franciscanos idos de Manila, e cuja igreja se encontrava em ruínas em 1780 - o Convento de São Domingos — que tem as suas origens por volta

38 AHU, caixa 6, doc. 47, fol. 9. Em 1774 existiam em Macau: 109 portugueses (reinóis), 200 filhos de portugueses, 669 naturais e nhons, 12 chineses cristãos, 23 clérigos seculares, 5 minoristas e tonsurados, 18 religiosos, 30 religiosas, 527 mulheres casadas, 321 viúvas, 1354 solteiras, 627 crianças, 6 indianos, 1060 escravos, 9 libertos e 2 estrangeiros, num total de 4973 moradores (AHU, caixa 8, doc. 6).

39 Carta do Senado à rainha D. Maria I (12-01-1788), in Arquivos de Macau, (1972, p. 52-54). Em 1791 a população de Macau contava com 5233 não chineses, 22000 chineses, num total de 27233 habitantes (AHU, caixa 19, docs. 20-21).

40 AHU, caixa 9 doc. 8. 
de 1586, com a ida de religiosos das Filipinas para Macau, tendo a igreja actual sido erguida/remodelada em 1721 —, e o Convento de Santo Agostinho, fundado no século XVI por padres espanhóis das Filipinas.

A primeira quadra inicia-se a construção da imagem negativa do enclave, encontrando-se a dimensão sínica (a maioria da população) praticamente ausente do texto, que se ocupa sobretudo da minoria lusa, com quem o poeta teria privado durante a sua curta estada em Macau. O sentimento anti-clerical e a imagem negativa e carnavalizada do espaço exótico são transportados para a segunda quadra, que nos apresenta um edifício de prestígio, a Sé Catedral, "com catorze prebendados, sem ceitil”, rodeada por miséria social e humana, prostituição em larga escala e uma centena de portugueses, número corroborado pelas fontes históricas que listam 100 portugueses idos de Portugal (reinóis) em Macau nos anos de 1773, 1774. ${ }^{41}$ Como revelam as fontes históricas, a prostituição era efectivamente um fenómeno generalizado no período em que Bocage visita o território. $\mathrm{O}$ peso da moral católica recai sobre as mulheres da cidade que vendem serviços sexuais e castiga-as ao recolhê-las no asilo de Maria Madalena e ao enviá-las para Timor. Mas os lucros do negócio da prostituição eram tão elevados que o bispo encontra oposição e um conflito com o desembargador Lázaro da Silva Ferreira, resignando o seu cargo quando o governo lhe ordena que feche o recolhimento. As prostitutas são 'corrigidas' no referido asilo e aprendem a coser roupa, e as reclusas incorrigíveis são enviadas para a prisão timorense, encontrando-se subjacente a essa medi-

41 AHU, caixa 6, doc. 47; caixa 8, doc. 6; caixa 19, doc. 17. Em 1791 a designação "português" (reinol) deixa de aparecer na documentação, sendo, como veremos adiante, a diferenciação da população a partir de então feita com base no sexo e estado civil (AHU, caixa 19, doc. 17, veja-se também caixa 12, doc. 9). 
da a representação do papel, das funções sociais da mulher europeia 'de boa conduta', que se deveria dedicar à vida doméstica. Por esta altura, o Senado informa D. João, príncipe regente de Portugal, que os estrangeiros, ao estabelecerem-se de forma permanente em Macau, "acarretariam" as suas diversas religiões, adiantando que a riqueza destes "tem conduzido lastimozamente à prostituição muitas Donzellas pobres [e] o seu luxo, costumes, vícios também $[\ldots]$ conduz $[\ldots]$ a muitas despezas", ${ }^{42}$ ideia repetida pelo bispo Marcelino José da Silva, em 1793, ao afirmar que alguns moradores vendem os serviços sexuais das suas filhas, mulheres e irmãs aos europeus, revoltando-se quando estes não os aceitam (TeIXeIrA, 1984, p. 679). Surgem assim na segunda metade do século XVIII medidas moralistas por parte da Igreja para erradicar a prostituição (VALE, 1997, p. 141-144, 168-169) que Bocage refere. O referido edifico da Sé Catedral, dedicado à Natividade de Nossa Senhora, encontrava-se numa das zonas mais elevadas da cidadela cristã, datava de 1622 e recebera poucos melhoramentos. Com é sabido, a 'prebenda' é o direito de um eclesiástico a receber um subsídio, mas, na altura, o Senado alegava não ter dinheiro para pagar prebendas. Os "catorze prebendados" referidos no segundo verso da segunda quadra eram os então três cónegos (José Antunes, José Simões de Carvalho e Gregório João Nepomuceno) e os demais padres que faziam serviço na Sé (por falta de cónegos) como capelões e cantores, bem como os prelados, que, como não recebiam o ceitil, requereram, por volta de 1785, à rainha D. Maria I que lhes fossem dadas as côngruas pelo rendimento da Câmara de Macau (VAle, 1997, p. 137-150). A ausência do pagamento de côngruas era decerto um dos motivos para a referida falta de zelo do clero secular. O

42 AHU, caixa 21, doc. 37, fls. 3-4 (31-12-1800). 
"Mapa da População de Macau" anexo à carta do governador de Macau (4-12-1791) lista os residentes das três freguesias de Macau, dos conventos e do Seminário de São José, e, ao contrário do que acontecera em 1773, já não os divide em "portugueses", "filhos dos portugueses e mestiços", "Chineses cristão ou naturais" e "escravos", ${ }^{43}$ mas em: mulheres e homens casados, solteiros e viúvos, crianças até aos doze anos, servos e escravos, chineses cristãos e enfermos. ${ }^{44}$

As três freguesias referidas são a da Sé, a de São Lourenço e a de Santo António, ${ }^{45}$ cujas empobrecidas igrejas exibiam apenas madeiras podres ou atacadas pela formiga branca ${ }^{46}$ ("ornatos é pau”). O vigário-geral (governador do bispado) entre 1780 e 1791 foi o padre António Jorge Nogueira, e se, de acordo com o soneto, o rei não detinha poder na cidade, as fontes revelam que também não havia bispo desde 1778, quando D. Alexandre Guimarães fora forçado pelo rei a regressar a Portugal. Já o vigário-geral era o governador do bispado, não havendo também promotor de justiça do Juízo Eclesiástico entre 1789 e 1790 (TeixeIra, 1997, p. 287). O sucessor de D. Alexandre Guimarães, o bispo Marcelino José da Silva, foi nomeado em 1789, mas só chegaria a Macau em Setembro de 1791, e, já no enclave, ecoa o conteúdo do poema de Bocage ao queixar-se, em carta a Martinho de Melo e Castro (1791), que a população vive como se não fosse cristã, criticando o luxo, o ócio e a prostituição. ${ }^{47} \mathrm{O}$ território carnavalizado é assim metaforizado e descrito como um peque-

\footnotetext{
43 "Relação das Casas Ricas de Macau": AHU, caixa 6, doc. 47.

44 AHU, caixa 19, doc. 17.

45 Em 1774, a freguesia da Sé, a mais populosa, tinha 2114 residentes, a de São Lourenço 1793 residentes e a de Santo António 1017 residentes (AHU, caixa 8, doc.6).

46 Frei José de Jesus Maria (1988, vol. 1, p. 150); AHU, caixa 7, doc. 41.

47 AHU, caixa 19, docs. 15 e 20.
} 
no "curral" (a cidadela cristã envolvida e defendida por muralhas) delimitado de um lado pelo rio das Pérolas, do outro pelas Portas do Cerco, outra cerca metafórica e a que possivelmente o sujeito poético também aludiria jocosamente através do trocadilho 'Cerco-cerca do curral', animalizando, portanto, a sociedade local e hiperbolizando algumas das suas características negativas. O curral poderá remeter também quer para o isolamento geográfico e politico de Macau, território chinês sob co-administração portuguesa, quer para a atitude passiva dos moradores face às exigências do Mandarinato, até porque dependiam dos chineses para obter víveres ${ }^{48}$ mão de obra e desenvolver o comércio. Essa obediência e as relações cordiais que Bocage poderá eventualmente ter criticado - ao ecoar discursos políticos que se ouviam em Lisboa - foram, no entanto, um dos fortes motivos da sobrevivência de Macau até 1999, até porque o território nunca foi uma colónia portuguesa, e os portugueses nunca aí tiveram plenos poderes, nem total soberania. Aliás o desrespeito pelas imposições chinesas teria levado ao abandono forçado do enclave pelos portugueses. $^{49}$

O primeiro terceto ocupa-se da dimensão militar e refere seis fortes, que, como sabemos, são: São Paulo do Monte (16121626), Santiago (1616-1629), Nossa Senhora da Penha de França (melhorado em 1622), Nossa Senhora do Bom Parto (c.1622), São Francisco (1622-1626) e Nossa Senhora da Guia (reconstruído em 1637-1638), não sendo obviamente contemplados os fortins de S. Jerónimo, de São Pedro e de São João. A dimensão militar enfraquecida é ineficaz, e são tantos os soldados como os

48 Em 1784, o próprio ouvidor Silva Ferreira refere o bloqueio de alimentos e o embargo ao comércio feitos pelos chineses aos portugueses até que estes últimos respeitem as suas exigências (AHU, caixa 16, doc. 11).

49 AHU, caixa 5, doc. 31. 
residentes portugueses referidos na estrofe anterior. Os militares contam com poucas armas e um só "tambor", marca da imagem acústica (silenciosa), que reforça a debilidade militar da cidade, que se encontra (e sente) abandonada por Lisboa. O número de soldados que o poema afirma residir no enclave é corroborado pelas fontes históricas, pois em Abril de 1783 Martinho de Melo e Castro informa que residiam em Macau 79 soldados, oito sargentos e dois tambores, que as tropas são comandadas por um sargento-mor e que cada fortaleza tinha um capitão. No Monte existia um capitão e cada sargento-mor tinha às suas ordens dois alferes, logo a guarnição militar da urbe rondava os 96 militares, ${ }^{50}$ um número próximo do avançado pelo soneto de que nos ocupamos, os cem militares que, em 1775, o bispo D. Alexandre da Silva Pedrosa Guimarães considerava ser o número ideal para defender a urbe. ${ }^{51}$

O segundo terceto revela o fraco nível da educação local ao criticar o 'Colégio' como "mau”, instituição que poderia ser: a) o abandonado Colégio de Madre de Deus, fundado pelos Jesuítas em 1594, b) o Colégio de São José, fundado também pelos Jesuítas em 1732 e que a partir de 1784 foi entregue aos Lazaristas, ou c) a escola elementar onde ensinava o clérigo António José Sales, a Escola de Ler, Escrever e Contar. O Colégio de Madre de Deus encontrava-se degradado, tendo sido já demolidas algumas oficinas que estavam em ruínas. Recorde-se os Jesuítas foram expulsos de Portugal em 1759 e do império em 1762, tendo a qualidade da educação decaído por falta de substituição das instituições de

50 Ver parágrafo 10 das "Instruções a D. Frederico Guilherme de Sousa, governador e capitão-general da Índia” (Múrias, 1988, p. 3), e AHU, caixa 6, doc. 47 e António Martins do Vale (1997, p. 5).

51 Cartas de D. Alexandre da Silva Pedrosa Guimarães para Martinho de Melo e Castro, 08-01-1775 e 01-12-1777: AHU, caixa 8, docs. 6, 8 e caixa 11, doc. 25. 
ensino da Sociedade de Jesus. Aliás, o amigo de Bocage indirectamente visado no poema, o desembargador e governador interino Silva Ferreira, informava Goa no final de 1784, que

[...] depois da extinção dos Jesuítas cessam aqui as escolas. Não houve mais uma cadeira de latinidade, nenhuma de moral ou teologia. Quem quis aprender foi Manila, e alguns para Goa e outros a quem os meios faltavam ficaram aqui, ouvindo lições de algum clérigo antigo [...]. O professor régio [Santos Baptista e Lima] com ordenado de 500 táeis ainda não formou um só estudante bom. As religiosas não dão aulas, nem estes conventos têm mestres. (TeIXeIRA, 1997, p. 287)

A ausência de um sistema educativo eficaz enfatiza a ignorância e a má formação da população local que facilitariam a corrupção e a defesa sobretudo dos interesses próprios dos moradores do enclave. $\mathrm{O}$ terceto final contempla ainda a administração local e critica o abandono de Macau por parte de Lisboa. Enquanto o todo-poderoso Senado tem mais poder que o governador, a Coroa abandonou o enclave, que vive na miséria e à mercê dos interesses pessoais dos senadores. O soneto assume-se como uma sintética e irónica enumeração que termina com uma crítica ao abandono de Macau e que exige um leitor informado e competente relativamente à história de Macau, pois muita da informação é sugerida nas entrelinhas. Ao longo de 14 versos, Bocage carnavaliza o enclave do seu tempo. Na primeira quadra critica os poderes administrativo e religioso, bem como a população transgressora, enquanto estabelece, na segunda quadra, um paralelismo simbólico ao equiparar a miséria da paisagem humanizada ou arquitectónica à da paisagem humana, ocupan- 
do-se dos edifícios e da sociedade decadentes. O primeiro terceto detém-se na dimensão militar enfraquecida, nas freguesias pobres e na ausência de um sistema de justiça eficaz, e, por fim, o segundo terceto refere o baixo nível da educação e da administração locais, enquanto critica o poder central colonial.

Uma das questões levantadas pela análise do soneto de Bocage é a capacidade de a poesia representar o mundo extra-literário. A partir do poema, podemos atestar a possibilidade da poesia para representar ou sugerir, mesmo que de forma subjectiva e até parcial (porque política), a realidade externa ao texto ao encapsular episódios, práticas, ideias e até conceitos de cariz historico-político, ou seja, os referentes extra-literários que não devem ser confundidos com os elementos reais assim poetizados. A relação entre poesia e história e a presença desta última na literatura enquanto tema e artifício narrativo supõe, desde logo, a existência de referentes extratextuais verificáveis, que sustentam parte da rede de significações do texto poético, mas que não devem ser considerados reflexos exactos da realidade. Até porque, como demonstra o soneto de Bocage, estes podem ser desfamiliarizados, ficcionalizados ou carnavalizados, por exemplo, em prol de interesses pessoais. Deveremos assim também ponderar as possibilidades e liberdades da poesia enquanto género, e da história como fenómeno capaz de ser textualmente representado. Se em 1972 Eduardo Lourenço refere, em O Labirinto da Saudade: Psicanálise do Destino Português, o longo processo literário de mitificação do Oriente (Lourenço, 1978, p. 2), o poema de Bocage de que nos ocupámos poderá ser considerado um exercício (com fins políticos e 'partidários') de crítica colonial e de desmistificação da empresa, missão e presença lusas nesse reduzido espaço cronotopicamente distante, construído e mantido nas fraldas do Império do Meio e do império português. O objectivo político 
do soneto, que aliás não tem grande valor literário, faz com que o sujeito poético omita muitas outras dimensões que enriquecem o território - a comercial, a económica, a intercultural e a chinesa -, e fá-lo estrategicamente em prol de uma enumeração descritiva deveras ideológica e parcial, como o costumam ser os universos carnavalizados.

\section{Bibliografia}

\section{Fontes manuscritas}

Arquivo Histórico Ultramarino (Lisboa)

Macau:

caixa 6 , doc. 47 ,

caixa 7 , doc. 41 ,

caixa 8 , docs. 6,8 ,

caixa 9 doc. 8 ,

caixa 11 , doc. 25 ,

caixa 17 , docs. $3,26,68$,

caixa 18, docs. 21, 34, 44,

caixa19, docs. 7, 15, 17, 20-21, 30, 34,

caixa 20, docs. 10-11,

caixa 21 , docs. 5,37 .

\section{Fontes Impressas}

Arquivos de Macau, $3^{\mathrm{a}}$ série:

vol. 16, n. 4,1971

vol. 17, n. 1, 1972.

Beckford, William. Italy: with Sketches of Spain and Portugal. v. 1. Londres: Richard Bentley, 1834. 
Burton, Richard Francis. Goa and the Blue Mountains or Six Months of Sick Leave. Londres: Richard Bentley, 1851.

"Instruções a D. Frederico Guilherme de Sousa". In: Múrias, Manuel (ed.) Instruções para o Bispo de Pequim e outros Documentos para a História de Macau. Macau: Instituto Cultural de Macau, 1988.

Loureiro, Adolfo. No Oriente: De Nápoles à China. Lisboa: Imprensa Nacional, 1896-1897. 2 v.

Low, Harriet. Lights and Shadowes of a Macao Life: The Journal of Harriet Low, Travelling Spinster. v. 1. Woodinville: The History Bank, 2002.

Maria, Frei José de Jesus. Ásia Sínica e Nipónica. v. 1. Macau: Instituto Cultural de Macau, 1988.

Múrias, Manuel (Ed.). Instruções para o Bispo de Pequim e outros Documentos para a História de Macau. Macau: Instituto Cultural de Macau, 1988.

\section{Textos Literários}

Bocage, Manuel Maria Barbosa du. Opera Omnia. ed. Hernâni Cidade. Lisboa: Livrara Bertrand, 1969. . Obra Completa, vol. 2: Cantatas, Canções, Idílios, Epistolas,

Odes e Cantos. ed. Daniel Pires. Porto: Caixotim, 2005.

\section{Estudos}

Bakhtin, Mikhail. Problems of Dostoevsky's Poetics. Minneapolis: University of Minnesota Press, 1984a. 
Rabelais and his World. Bloomington: Indiana University Press, 1984b.

Batalha, Graciete Nogueira. Glossário do Dialecto Macaense: Separata da Revista Portuguesa de Filologia, vols. xv-xvii, p. 229-230, 1971, 1974 e 1977.

Bernstein, Michael Andre. When the Carnival Turns Bitter: Preliminary Reflections upon the Abject Hero. In: Monson, Gary Saul (Ed.). Bakhtin: Essays and Dialogues on his Work. Chicago: University of Chicago Press, 1996. p. 9-121.

Berrong, Richard M. Rabelais and Bakhtin. Londres: University of Nebraska Press, 1986.

Booker, Marvin K. Techniques of Subversion in Modern Literature: Transgression, Abjection, and the Carnivalesque. Gainesville: University of Florida Press, 1991.

Bové, Paul A. Poetry against Torture: Criticism, History and the Human. Hong Kong: Hong Kong University Press, 2008.

Braga, Teófilo. História da Literatura Portuguesa, Bocage, Sua Vida e Época Literária. Porto: Livraria Chardron, 1902.

Bristol, Michael. Carnival and Theater: Plebian Culture and the Structure of Authority in Renaissance England. Nova Iorque: Methuen, 1985.

Castle, Terry. Masquerade and Civilization: The Carnivalesque in Eighteenth-Century English Culture and Fiction. Stanford: Stanford University Press, 1987.

The Carnivalization of Eighteenth-Century English Narrative. PMLA, v. 99, p. 903-916, 1984. 
Chedgzoy, Kate. "For Virgins Buildings Oft Brought Forth": Fantasies of Convent Sexuality. In: D’Monté, Rebecca; PoHL, Nicole (ed.). Female Communities, 1600-1800: Literary Visions and Cultural Realities. Houndsmills: St. Martin's Press, 2000. p. 53-75.

Clark, Katherina; Holquist, Michael. Mikhail Bakhtin. Cambridge: Harvard University Press, 1984.

Coronato, Rocco. Jonson versus Bakhtin: Carnival and the Grotesque. Nova Iorque: Rodopi, 2003.

Danow, David K. The Spirit of Carnival: Magic Realism and the Grotesque. Lexington: The University Press of Kentucky, 1995.

Domingues, Mário. Bocage, a sua Vida e a sua Época: Evocação Histórica. Lisboa: Romano Torres, 1962.

Eagleton, Terry. Walter Benjamin or Towards a Revolutionary Criticism. Londres: Verso, 1981.

EISENBICHLER, Konrad. Introduction. In: EISENBICHLER, Konrad; Hüsken, Wim (Ed.). Carnival and the Carnivalesque: The Fool, the Reformer, the Wildmen, and others in Early Modern Theatre. Amesterdão: Rodopi, 1999. p. 7-18.

Emerson, Caryl. The First Hundred Years of Mikhail Bakhtin. Princeton: Princeton University Press, 2000.

Gardiner, Michael. The Dialogics of Critique: M. M. Bakhtin and the Theory of Ideology. Londres: Routledge, 1992.

Glazener, Nancy. Dialogic Subversion: Bakhtin. The Novel and Gertrude Stein. In: Hüsken, Ken; Shepherd, David (Ed.). Bakhtin and Cultural Theory. Manchester: Manchester University Press, 1989. p. 151-176. 
Gonçalves, Adelto. Bocage, o Perfil Perdido. Lisboa: Caminho, 2003.

Gossman, Lionel. Between History and Literature. Cambridge-MA: Harvard University Press, 1990.

Gurevitch, Aron. Medieval Popular Culture: Problems of Belief and Perception. Cambridge: Cambridge University Press, 1988.

Gusmão, Manuel. Da Literatura enquanto Construção Histórica. In: Buescu, Helena; DuARTe, João Ferreira; Gusmão, Manuel (org.). Floresta Encantada: novos caminhos da Literatura Comparada. Lisboa: Dom Quixote, 2001. p. 181-224.

Hirschkop, Ken. Introduction. In: HirschKop, Ken; Shepherd, David (ed.). Bakhtin and Cultural Theory. Manchester: Manchester University Press, 1989. p. 1-31.

Hutcheon, Linda. A Theory of Parody: The Teachings of Twentieth-Century Art Forms. Urbana: University of Illinois Press, 1985.

KrIER, Dan; Swart, William J. The Dialectics of Carnival: From Bakhtin to Baudrillard. In: Braun, Jerome; LANGMAN, Lauren (Ed.). Alienation and the Carnivalization of Society. Nova Iorque: Routledge, 2012. p. 135-168.

Ladurie, Emmanuel LeRoy. Carnival in Romans. Nova Iorque: George Brazillier, 1979.

Lindley, Arthur. Hyperion and the Hobbyhorse: Studies in Carnivalesque Subversion. Londres: Associated University Presses, 1996. 
Lourenço, Eduardo. O Labirinto da Saudade: Psicanálise do Destino Português. Lisboa: D. Quixote, 1978.

Marinho, Maria de Fátima; Topa, Francisco (coord.). Literatura e História: Actas do Colóquio Internacional. 2 v. Porto: Campo das Letras, 2004.

Marinho, Maria de Fátima. Um Poço sem Fundo: Novas Reflexões sobre Literatura e História. Porto: Campo das Letras, 2005.

Monteiro, Gomes. Bocage, esse Desconhecido. Lisboa: Romano Torres, 1943.

Morson, Gary Saul; Emerson, Caryl. Mikhail Bakhtin: The Creation of a Prosaics. Stanford: Stanford University Press, 1989.

Neff, Emery. The Poetry of History: The Contribution of Literature and Literary Scholarship to the Writing of History since Voltaire. Nova Iorque: Columbia University Press, 1961.

Palmer, Roundell. The Connections of Poetry with History, A Lecture. Londres: Whittaker, 1852.

PIres, Benjamim Videira. Os Extremos Conciliam-se: Transculturação em Macau. Macau: Instituto Cultural de Macau, 1988.

Platter, Charles. Novelistic Discourse in Aristophanes. In: BARTA, Peter et al. (Ed.). Carnivalizing Difference: Bakhtin and the Other. Londres: Routledge, 2001. p. 51-78.

Pope, Ethel M. India in Portuguese Literature. Nova Déli: Asian Educational Services, 1937.

PugA, Rogério Miguel. A World of Euphemism. Representações de Macau na Obra de Austin Coates: City of Broken Promises enquanto Romance Histórico e Bildungsroman. Lisboa: Fundação para a 
Ciência e a Tecnologia-Fundação Calouste Gulbenkian, 2009a. . A Presença Inglesa e as Relações Anglo-Portuguesas em Macau (1635-1793). Centro de História de Além-Mar, Universidade Nova de Lisboa-Universidade dos Açores, Centro Cultural e Científico de Macau, Lisboa, 2009b.

Riedel, Dirce Côrtes (ed.). Narrativa, Fiç̧ão e História. Rio de Janeiro: Imago, 1998.

Rolusns, Benjamin. Carmival's Dance of Death: Festivity in the Revenge Plays of Kyd, Shakespeare, and Middleton. Tese (Doutorado em Literatura Inglesa) - Georgia State University, 2012.

Rosa, Luís. Bocage, a Vida Apaixonada de um Genial Libertino. Lisboa: Presença, 2006.

Seixo, Maria Alzira. Literatura e História: Poética da Descoincidência em Peregrinação de Barnabé das Índias, de Mário de Carvalho. In: Marinho, Maria de Fátima; TopA, Francisco (Coord.), Literatura e História: Actas do Colóquio Internacional. v. 2. Porto: Campo das Letras, 2004. p. 231-241.

Stallybrass, Peter; White, Allon. The Politics and Poetics of Transgression. Londres: Methuen, 1986.

Stam, R. Subversive Pleasures: Bakhtin, Cultural Criticism, and Film. Baltimore: Johns Hopkins University Press, 1989.

Stewart, Marilyn. Carnival and Don Quixote: The Folk Tradition of Comedy. In: Cowan, Louis (Ed.). The Terrain of Comedy. Dallas: Dallas Institute of Humanities, 1984. p. 143-162.

Stronm, Paul. Hochon's Arrow: The Social Imagination of Fourteenth-Century Texts. Princeton: Princeton University Press, 1992. 
Teixeira, Padre Manuel. Toponímia de Macau. v. 2. Macau: Instituto Gultural de Macau, 1997. . Macau no Século XVIII. Macau: Imprensa Nacional de Macau, 1984.

Tennenhouse, Leonard. Power on Display: The Politics of Shakespeare's Genres. Nova Iorque: Methuen, 1986.

Vale, António Martins do. Os Portugueses em Macau (1750-1800): Degredados, Ignorantes e Ambiciosos ou Fiéis Vassalos d'El-Rei? Macau: Instituto Português do Oriente, 1997.

Véscio, Luiz Eugénio; Brum, Pedro (Org.). Literatura e História. São Paulo: Edusc, 1999.

VIcE, Sue. Introducing Bakhtin. Manchester: Manchester University Press, 1997.

Vicks, Meghan Christine. The Postmodern Oranus: Carnival and Abjection in Victor Pelevin's Homo Zapiens. Tese (Doutorado) - Universidade do Colorado, 2007.

WANG, David Der-wei. The Monster that Is History: History, Violence, and Fictional Writing in Twentieth-Century China. Berkeley: University of California Press, 2004.

Young, Robert. Back to Bakhtin. Cultural Critique, v. 2, p. $71-$ 92, 1985-1986.

PugA, Rogério Miguel. A carnavalização hiperbólica da Macau Setecentista num soneto de Bocage (c.1789) em prol da figura do ouvidor Lázaro da Silveira Ferreira. In: Simas, Monica (Org.). Estudos sobre Macau e outros orientes. São Paulo: Paulistana, 2017. p. 224-259. 